\title{
Exercising Library and Information Literacies Through Alternate Reality Gaming
}

\author{
Adam Jerrett \\ Department of Information Science, University of Pretoria, Pretoria, South Africa \\ Theo J.D. Bothma \\ Department of Information Science, University of Pretoria, Pretoria, South Africa \\ Koos de Beer \\ Department of Information Science, University of Pretoria, Pretoria, South Africa
}

\begin{abstract}
Purpose

Teaching students/library patrons 21st century literacies (such as information and library literacies) is important within a library setting. As such, finding an appropriate manner to teach these skills in a practical manner at tertiary level is important. As vehicles for constructivist learning, games provide a unique opportunity to teach these 21st century literacies in an engaging, practical, format. This article discusses the implementation of an alternate reality game (ARG) to teach these literacies through gameplay.
\end{abstract}

\section{Approach}

An ARG was designed and developed where the core gameplay tasks taught and exercised 21st century literacies. The game, once completed, was then analysed as a case study to determine the effectiveness of the game-based approach to literacy learning.

\section{Findings}

Throughout the play of the game, players spent increasingly more time in the library, often using it as a common meeting point during play. Players reported that they learnt or exercised the skills that each game task focused on, additionally noting that the game-based context made the process of learning and exercising these skills more enjoyable.

\section{Value/Originality}

The findings suggest that the creation of games, whether real world or digital, may be useful in engaging students/patrons with 21st century literacies as well as with their local library. The documentation of a successful ARG to teach 21st century literacies provides a model for future research to follow when designing engaging library-oriented games.

\section{Article Classification}

Research Article

\section{Keywords}

Alternate reality game, information literacy, library, 21st century literacies, teaching, constructivist teaching, game-based learning 


\section{Introduction}

The teaching and exercising of specific skill sets through practical application is becoming increasingly important in the 21st century's information age (Gee, 2003). As such, the idea of "actionable" theoretical knowledge has become a key component of the creation and administration of an effective, "authentic learning" experience (Galarneau, 2005).

The development of core information literacy competencies such as information relevance, information location, search strategies and information retrieval (de Boer et al., 2011) is thought to be an invaluable skill set for the use of academic libraries in academic institutions (Owusu-Ansah, 2004).

To support this, various academic institutions offer modules or programs that aid in the acquisition of such skill sets (Badke, 2005). The University of Pretoria presents a compulsory module in this regard to all students who register at the university (University of Pretoria, 2016).

However, researcher observation shows that students traditionally have trouble engaging with this module due to its compulsory nature and a lack of initial understanding regarding the module's importance. This is not uncommon, as it is reported that students of similar modules in other institutions struggle to understand the concept of information literacy and its skills (Maybee, 2006).

As a result, the lack of student engagement results in a barrier to learning (Whitton, 2011). Digital games have been suggested as a solution to stimulating engagement within a learning environment (Whitton, 2011).

This article discusses the design of an alternate reality game (ARG) that teaches and exercises information literacy competencies in an engaging and entertaining manner. In this regard it extends work done by De Beer and Holmner (2013) wherein they propose that an ARG designed to teach library and information literacies would be a useful contribution to the existing body of knowledge.

The ARG was examined as a case study (Gerring, 2004; Pickard, 2013, p. 101; Yin, 2013). The data collection techniques used were non-participant observation (Patton, 1987, p. 81; Pickard, 2013, p. 229), document analysis (Pickard, 2013, pp. 252-254), log file analysis (Pickard, 2013, p. 256), questionnaires (Pickard, 2013, p. 207) and focus groups (Gorman et al., 2005; Powell et al., 1996; Stewart and Shamdasani, 1990).

It is important to note that while the case was implemented at the University of Pretoria, and findings are not generalisable due to the study's qualitative nature, the approach taken to Nomad's development may be applicable to academic institutions and libraries in general (see section 6 for example puzzles). The ARG's design, detailed fully by Jerrett (2016), may additionally be replicable across institutions with similar results.

The choice to create an ARG rather than a traditional game laid in the benefits unique to ARGs: players play the game in the real world. Because players experience an ARG in first person, they have the ability to make choices that can fundamentally change the game in real-time. It is this sense of agency that makes the ARG genre so compelling and immersive (McGonigal, 2003a). This real-world context also allowed the experience to feel authentic and relevant to the lives of the players, and is discussed further in section 3.2.1. Additionally, ARGs place emphasis on collaboration and the use of multiple media, making the experience engaging and suitable for larger student groups. This emphasis on collaboration 
and multimedia mirrors aspects of the traditional education system. As such, ARGs complement the existing system, rather than replacing it, allowing it to be used complementary to traditional instruction (Zhang and Nunamaker, 2003).

This article continues by discussing aspects of the ARG genre that makes it unique when compared to traditional or digital games. Following this a narrative outline of the ARG itself, named Nomad, is presented. Nomad's puzzles and the learning outcomes intended for each of these puzzles are discussed. The findings of Nomad are then discussed before conclusions are made regarding the suitability of ARGs as 21st century literacy vehicles.

\section{Game-Based Learning}

Games are frequently used as teaching tools due to their highly practical nature and the approach they inherently take to the teaching of various literacies (Gee, 2003). This method, and the way in which it is applied for information literacy teaching is discussed below.

\subsection{Constructivist Teaching}

The learning theory of constructivism focuses on the construction of a personalised learning path through some contextualised environment (such as a real-world environment or virtual environment). As learners explore these environments they construct new knowledge of the environment based on the integration of this knowledge with previous knowledge and contexts (Wadsworth, 1996). Research argues that games inherently adhere to these constructivist principles as the play of any game is an active learning experience within the system (Dickey, 2006; Galarneau, 2005; Gee, 2003). As players play a game, they plot their own path through the game, and thus through the learning experiences these games provide.

Multi-literacy teaching in traditional environments is also inherently constructivist, as 21st century learners need to contextualise new knowledge from various types of sources based on their existing contexts in an increasingly globalised world (Cazden et al., 1996). With these multiliteracies inherently practised in games (Gee, 2003), including alternate reality games (Bonsignore et al., 2012), it can be seen that constructivist principles are used extensively in games, thus showing that constructivism is a useful educational perspective for game-based learning applications.

\subsection{The Use of Games for Creating Motivation}

As noted earlier, games are used more often as teaching tools in the $21^{\text {st }}$ century (Gee, 2003). The rise of "casual" or "social" games, heralded by the dawn of social media platforms like Facebook, has given potential players more access to games and, as a result, game awareness has risen: more people play, and the concept of "gaming" is becoming a more-accepted social norm (Ines and Abdelkader, 2011). The existence of casual games on these platforms additionally ties into social validation, as achievements can be shared with friends, who may congratulate the player (validating their achievement) and in turn may choose to also participate in the game as a result.

It then becomes important to discuss how games affect their players. Gentile and Gentile (2007), for example, suggest that there is a correlation between playing violent games and aggressive tendencies, and thus denote the necessity of varying gameplay habits. 
Their findings strengthen a case for exposing students to educational games that lack these violent tendencies. Exposing players to games where non-violent conflict resolution is a game goal helps showcase the potential of games as forces of positive change. Games such as Urgent: Evoke (Waddington, 2013) and World Without Oil (Rusnak et al., 2008) are successful examples of positive educational games in this regard. These games are also both alternate reality games, which strengthens the case of Nomad, as an ARG itself, as a positive learning tool.

In contrast to Gentile and Gentile's (2007) warning against playing violent games, Granic et al. (2014) focus on the positive effects of play, denoting that games aid motivational, social, emotional and cognitive development in children. These positive results suggest that serious games can be developed to target these areas of growth and, as a result, teach effectively.

In pursuit of teaching effectively, (Hsu and Lu, 2007) note that perceived enjoyment, ease of use and cohesion are all elements that result in positive outcomes for brand loyalty. When applied to educational games these elements - the creation of an enjoyable, easy to play game that links with the educational content - can help increase motivation to engage with the educational content. This selfdriven motivation, or autonomous motivation (Koestner et al., 2008), allows students to more deeply engage with the learning content while engaging with the game, thus increasing the likelihood of game content (and learning outcome) retention.

Lastly, educational games can examine a wide range of intrinsic motivations to inform their design. Malone and Lepper (1987) detail a variety of intrinsic motivations that are present in learning, and that are also satisfied by games. These include: fantasy, challenge, curiosity, control (Malone and Lepper, 1987). Additionally, various intrapersonal motivations exist both in learning and games. These include co-operation, competition and recognition. It is notable that these latter motivations are often present in alternate reality games due to the communal nature of play in the genre (see 3.2.3).

\subsection{The Use of Games in Information Literacy Teaching}

Broussard (2012) reviews various types of games that can be utilised by libraries for information literacy teaching. These game types range from non-digital trivia board games and role playing games to slightly digital social games (that utilise networking to allow for competition and collaboration) and casual games (that are largely physical but incorporate digital elements) to highly digital games that employ multiple media types such as mixed reality (physical and virtual) and alternate reality games.

The best practices Broussard (2012) suggests for these game types range from simple anecdotes ("keep it simple" and "make it fun") to more complex suggestions of how best to market it and how to control player progression. In suggesting how to go about implanting these best practices, Broussard (2012) suggests the use of game design elements to guide information literacy game design. Nomad follows this suggestion.

Smale (2011) reviews a multitude of information literacy video games to determine their usefulness, and games' usefulness in general, in teaching information literacy skills. She notes in this examination that various factors must be taken into account, such as development time, development cost, access to game platforms of materials externally from the learning environment and the time used as learning period for students to get acquainted with the game (Smale, 2011). Markey et al. (2008) note that 
information literacy games should additionally be incentivised in order to promote gameplay. This suggests that digital educational games may not be as intrinsically motivational as they initially appear.

Despite this, Smale (2011) asserts that games are nevertheless useful motivators to help engage students in the learning process, as their play (whether incentivised or not), is a way to keep students engaged beyond initial lectures given through the traditional classroom approach. Showing students the value of information literacy skills in a practical, ludic context can allow for greater retention of these skills (Smale, 2011).

One such game developed for the purpose of teaching information literacy skills is BiblioBouts (Markey et al., 2014). BiblioBouts tasks students with the final goal of building of a bibliography to use for a final module assignment through phased gameplay. These phases include "gathering" and "self-selecting", where students find and narrow down the most relevant sources for their assignment. During "rating" and "choosing-the-best" phases, the player group collectively evaluates the most relevant sources gathered by the group, building a joint 10 source bibliography. Players are then scored individually in the "scoring" phase based on the overall relevance of their sources, along with other factors such as the age of their sources and the amount they collected. The winner of the game is the player with the highest score (Markey et al., 2014).

Players criticised the length of the game itself, as it is played over the semester in which the module it is integrated into is presented. This overlong running time meant that players would often become demotivated to play as responsibilities external to the game mounted throughout the semester (Markey et al., 2014, p. 118). Additionally, despite the usefulness of the joint bibliography and the ability to access the bibliographies of other players during the module's final assignment, it was reported that many players did not make full use of this availability, only utilising a fraction (17/142) of the available sources (Markey et al., 2012). A reason for this may be information overload experienced by the players, due to the large amount of sources generated by all the players.

Despite these criticisms, however, it was generally noted by the players that Bibliobouts was a successful educational tool that helped in teaching and familiarising themselves with information behaviour practices (Markey et al., 2012).

\section{The Uniqueness of ARGs}

This article describes the creation of an alternate reality game for game-based learning instead of a traditional game due to unique characteristics of the ARG genre. In explaining these characteristics, the genre is discussed below.

\subsection{Defining ARGs}

It is necessary to define ARGs in order to adequately discuss them within this article. Definition of the term has previously proved difficult, as various sources tend to focus on different aspects of the genre. However, an analysis and amalgamation of aspects of 15 sources (Alternate Reality Gaming Network, 2002; Bono and Breeze, 2008; Bonsignore et al., 2012; Chess and Booth, 2013; Dena, 2008; Gurzick et al., 2011; Hakulinen, 2013; Hansen et al., 2013; Kim et al., 2008; Martin and Chatfield, 2006; McGonigal, 2003b; Ornebring, 2007; Stewart, 2008; Szulborski, 2005; Unfiction, 2002) presents the following succinct definition: 
"An alternate reality game is a game that focuses on delivering a platformless, fragmented narrative experience to its players. This narrative is progressed through the collaborative solving of puzzles that, along with the narrative, is delivered through the use of multiple mediums (audio, text, and video, amongst others) and technologies that utilise these media. The use of these realworld mediums allows the game to interface with the reality of the players, allowing for a more immersive play experience than is provided by other media. It is the use of these same technologies that allows the players to interact with the game and possibly, through their actions, alter the very narrative it attempts to deliver."

(Jerrett, 2016)

\subsection{Important Aspects of the ARG genre}

An examination of the above definition highlights three important aspects of the play of an ARG: an immersive experience, the exploration of a narrative and the collaboration of players towards goals. These aspects are discussed below.

\subsubsection{Authenticity and Immersion}

Part of the large potential and allure of the alternate reality game genre is the notion that its context unfolds in the reality inhabited by its players (McGonigal, 2007). It is here that the mantra "this is not a game" (often abbreviated as "TINAG" or "TING") becomes important.

At its core, "this is not a game" can simply represent a system's denial of a potential ludic nature (Szulborski, 2005, p. 19). This is important in ARGs due to their integration with the player reality. Game artefacts that make use of multiple media work as they do in real life: phone numbers, email addresses and blogs related to game content all masqueraded, during the game, as real, working artefacts (McGonigal, 2003b).

Another interpretation of "this is not a game", however, invokes Suits' (1978, p. 34) lusory attitude: acceptance of, and abiding by, the game's rules for the preservation of the game's intended experience. In this interpretation, players are aware that they are playing a game, but actively choose to ignore this fact (Stenros et al., 2011). McGonigal (2003a) calls this the "performance of belief" or "the Pinocchio effect": players pretend to believe, because the act of belief creates a more engaging experience.

The creation of this authenticity is a key benefit the ARG genre possesses over traditional games. Skill learning is promoted as a result, as players do not simply help avatars to learn a skill, but rather learn it themselves (Lee, 2006). This leads to the creation of an "authentic learning environment" (Galarneau, 2005). Because of this, adherence to the "this is not a game" aesthetic by either the players or the game helps reinforce both authenticity and skill learning and acquisition through the repetition of its mantra: "This is not a game, and you are not playing. This is real, and you are doing."

\subsubsection{Exploratory Narrative}

As noted earlier, ARGs utilise multiple forms of media in order to convey the game's narrative. The scattering of this narrative across these media forms thus presents as "transmedia fragmentation" (Dena, 2008). This fragmentation inherently allows for collaboration, as, due to the genre's scale, it is unlikely a single player would find every narrative fragment, let alone make sense of such a large pool of 
fragmented information likely discovered out of sequence with the game chronological narrative (Dena, 2008).

Because of these large narratives that play out in real time, it is possible for players who do not follow the game from the start to become easily lost. This is eased by the frequent publication of "game guides" by player communities, wherein players document their journey through the game, as well as their findings (Dena, 2008). It is important to note that this documentation is often not explicitly required by the game, but the content synthesis and collaboration that occur during guide creation are inherent learning experiences (Bonsignore et al., 2012).

\subsubsection{Collaborative Play}

The collaborative play engaged in by the community within ARGs is the main driving force of the game, dubbed by McGonigal (McGonigal, 2003b) as the "collective detective". The "collective detective" collaborates within an ARG to construct a shared meaning of the game world. Individuals within the collective examine the shared narrative presented by the game and discuss their understanding of that narrative with other individuals. This discourse leads to an overall greater shared understanding of the game system and narrative over time, as perspectives and opinions on aspects of the game contribute to a greater overall understanding of the "bigger picture".

This act of shared meaning making is another important educational opportunity inherent in the ARG genre whereby information literacy skills are exercised regardless of the game's narrative or ludic contexts.

\subsection{Learning through ARGs}

The Unified Metaliteracies Framework (UMF) presents a direct link between ARGs and the exercise of 21st century literacies. Bonsignore et al. (2012) posit that the play of alternate reality games, due to their design and genre, inherently practices 21st century literacies such as technology, communications, media and information literacies.

Due to the combination of literacies exercised during ARG play, Bonsignore et al. (2012) propose a Unified Metaliteracies Framework (UMF) for Transmedia Practices. This framework consists of seven categorisations of actions practiced to exercise 21st century literacies: gather, make sense, manage, solve, create, respect and collaborate.

- "Gather" refers to the finding of information segments, trailheads and hooks into the ARG and evaluating their relevance, authenticity and placement within the alternate reality. This also involves the separation of game artefacts from real-world objects or red herrings.

- "Make sense" refers to the aggregation of gathered information, using skills possibly taught and exercised during earlier gameplay, to form narrative and gameplay-based conclusions about the nature of the alternate reality.

- "Manage" refers to the careful organisation of these conclusions for personal, communal and/or archival use. These organised conclusions can be compiled into game guides or similar assets for future use.

- "Solve" refers to what the researchers consider one of the most vital parts of ARG gameplay and design - the ability to solve problems or puzzles in order to advance the game's narrative. 
- "Create" refers to the player ability to, through agency, produce artefacts that may exist either within the alternate reality's fiction (for gameplay-related reasons) or external from it (such as game guides or similar assets, potentially to aid new players).

- "Respect" refers to the social aspect of play within alternate reality games where, due to the potentially large and diverse player base, a respect for culture, ethics and legal systems is employed within the community in order to facilitate collaboration.

- "Collaboration" manifests in alternate reality games through their design, as well as the above "respect" category. ARG players must collaborate in order to fully participate in gameplay. This is often done through social media and Web 2.0 tools, further exercising communications and media literacies.

\subsection{Educational ARGs}

Multiple educational ARGs have been developed for a variety of educational purposes in tertiary institutions. Early educational ARGs that inspired Nomad's design include ViolaQuest (Whitton, 2009) and Who Is Herring Hale? (Piatt, 2009). These successful ARGs were used for teaching university orientation and induction, and thus often included some form of library usage or orientation in their designs.

ViolaQuest (Whitton, 2009) focused on campus orientation and induction, introducing new students to university life. This was achieved by having game events at various places on campus and throughout the surrounding city, as well as having players interact with each other to form social bonds. Whitton and Jones (2009) later discussed ViolaQuest's suitability for information literacy teaching.

Who Is Herring Hale? (Piatt, 2009), similarly, tasked students with utilising university resources (such as the library helpdesk and other on-campus services) to solve game puzzles in order to help a time traveller from the future "fix" the future by altering the past.

These ARGs paved the way for many other small-scale educational ARGs based on a variety of subject fields to be run at tertiary institutions.

Skeleton Chase (Johnston et al., 2012) was a health education ARG that set out to discover whether participating in an ARG could help players lose weight during their first year at a tertiary institution. The results were statistically inconclusive, but it was discovered that players were entertained by the experience nonetheless.

The Arcane Gallery of Gadgetry (Bonsignore et al., 2013) was used to teach students about American history by having them join a secret organisation that explored alternate versions of the historical content within the syllabus.

The Tower of Babel (Connolly et al., 2011) was an ARG designed around language learning. The ARG provided a ludic framing to language learning tasks, and was played online across multiple institutions. 
Black Cloud (Niemeyer et al., 2009) posed questions to its players regarding the effects of pollution of various ecosystems and biological life. Players attempted to defeat the "Black Cloud" by raising awareness of these issues in various ways within a city landscape.

Stop Toilworn Diamond (Hakulinen, 2013), an ARG dedicated to exercising computer science, had players decrypt files, find solutions to pathfinding algorithms as well as develop programs that could make sense of the strange datasets that players were given. In doing so, players stop a supercomputer from allowing a corporation from achieving world domination.

Project Velius, run at the University of Alabama, is another example of an information literacy ARG (Battles, 2014; Battles et al., 2011). The authors' reasoning for the creation of an ARG over a traditional game largely mirrors the reasons discussed in section 3.2. Nomad shares much in common with Project Velius, including a six week runtime, a team-based approach to asset development and game design, and a story-oriented design approach. However, Project Velius did not restrict targeting of the ARG to specific modules or courses, instead opening up play to the entire university. This lack of specific targeting hurt the participation of the ARG, which was only played by around 50 students based on feedback from web analytics (Battles, 2014; Battles et al., 2011). Web analytics, along with qualitative data from players suggested that the ARG was successful. However, like many small-scale ARGs, the game's success could only be judged by player response and designer observation (Battles, 2014; Battles et al., 2011).

Blood on the Stacks (Donald, 2008) is another example of a library ARG. Unlike Project Velius, however, Blood on the Stacks' was not implemented as a fully-fledged ARG. Instead, the author describes it as a "hybrid of an ARG, a self-guided mystery tour, an online multi-media game, and a treasure/scavenger hunt" (Donald, 2008). In this ARG hybrid, players are tasked with using the library, its website and the game website to solve a mystery regarding the theft of an artefact from the library itself.

Nomad succeeds these ARGs and based much of its design on considerations and design decisions made in each case study. As these ARGs were all presented as case studies due to the nature of the genre, Nomad is also presented as a case study within this article.

\section{The Target Audience}

When designing the ARG, designers planned to target students in two first-year modules and one thirdyear module. These modules were targeted partially due to lecturer co-operation regarding integrating clues to the game into these modules. Additionally, each of the targeted modules aimed to teach students skills that would be useful during gameplay. One first year module taught basic HTML skills, the other introduced students to information science and $21^{\text {st }}$ century literacies and the third year module taught students game design and analysis skills. Altogether, this target audience comprised approximately 300 students.

The skills taught in these modules allowed the designers an indication of the type of players who might participate in the ARG, and allowed the game to be designed accordingly. Players from the information science class group could contribute their understanding of information behaviour practice (information location, retrieval and search strategies, as mentioned earlier). Players from the HTML class group could 
use their understanding of how websites are built and structured to find clues within the code of game websites. Lastly, players from the game design class group could use their understanding of games and game design to guide players in the former two groups through complex gameplay segments.

The game website registered approximately 90 user accounts during gameplay. While it cannot be confirmed that these accounts were created by participants within the 300 student pool, it is assumed that the majority of these game accounts were created by students. Of these 90 accounts, approximately 20 accounts were active on in-game forums. This represents a conversion rate of $7 \%$ when considering the initial 300 student pool, a conversion rate that mirror's Urgent: Evoke's 5\% of users who had completed a significant portion of the game (McGonigal, 2010). The reason for such low conversion rates is due to the voluntary nature of the ARG genre: targeted players who are motivated and intrigued by games are simply more likely to play (Piatt, 2009; Whitton, 2009).

Of these 20 players, 11 players were interviewed during focus groups at the game's completion, and were additionally invited to complete a questionnaire which also garnered 11 responses. For the focus groups players were split into categories based on their degree of play. As a result, four focus groups were held: One four participant "active player" focus group for the most active players; one three participant "player observer" focus group for moderately active players and two "observer" focus groups consisting two participants each for players who briefly played, or merely knew about, the game.

The focus groups and questionnaire provided forums for a qualitative discussion of the players' experiences. Samples of the schedules for the focus groups and the questionnaire can be found in figures 1 and 2 . These results are discussed in section 7. 
- Discuss the enjoyment the players felt and possible hurdles to that

- Did they enjoy the game?

- Did things get boring?

- Did they get too busy with other aspects of life?

- Were there ever too many "live" puzzles or game elements that made the act of playing the game seem daunting?

- Was there ever too much waiting around?

- Was there a particular moment where you felt a personal sense of accomplishment during play (a particular puzzle, piece of narrative, live event)?

- Discuss the use of multimedia within the game.

- Were the various gameplay platforms intuitive (the blog, how they interacted with the characters etc.)?

- Did the various platforms of rewards enrich the game experience?

- Did these platforms integrate well and inform player context (audio giving context to images, video informing gameplay and narrative)?

- Do you feel the game was cohesive and complete?

Academic Skill Integration

- Discuss what the players feel the game taught them. Leave this open to player interpretation.

- Discuss the links between gameplay and skill exercise.

- Were the players consciously aware that the gameplay linked to information literacy skills?

- If they were, at what point did they make that connection?

- Did that context dilute the experience due to feeling too "academic" or "work-like"?

- Discuss how valuable the game was in terms of exercising information literacy.

- Do the players feel that their experiences during gameplay aided or contextualised skills taught and exercising during the University's Academic Information Management (AIM) modules?

- Do they feel that a "game framing" of Information Literacy skill exercises made them more engaging?

\section{Figure 1: Scheduled discussion points for the "active players" focus group}


Anter the Game

Ths section notes your reflectoons on your expernences with Namad.

16. Did you enjoy the game overalf?

ores

O Somewhat

No

\section{Please motlvate your answer to the above question.}

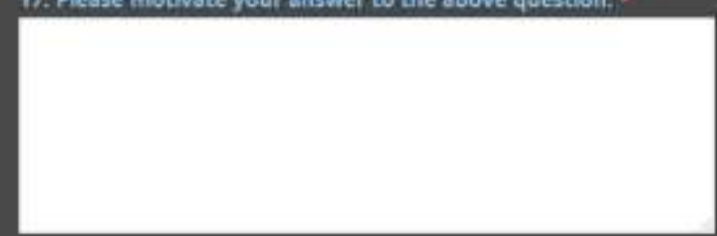

18. Describe a moment in the game. If any, where you feit a personal sense of accomplishmient:

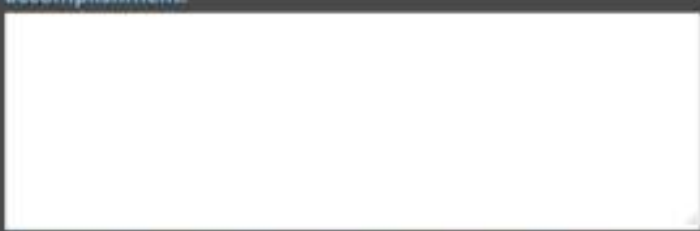

19. Select akills you feel that playing the game taughit you, if any.

Q. Searching for books in a library

Q Understanding and decoding diphers

Q Aademic relerencins

Q Internet saduch query canistruition

Q Searching the internet

Q Uving academic journal databases to scarch for articles

a using the Universty Library Portal

Q Using different technologeal platforms (mobile, PC)

D communicition with a community throughisocial media

Q using internet blogs, forums and soclal media

a croup problem solving

a Evaluating the relevance of information

C Rearranging informaticen to providecontext

E Explocitory or tangential learning

a other:

20. Do you feet that the gameplay helped contextualise the slalls taught and exercised during the Universibys Academic information Mansgement (AIM) modoles? Mark each response that applies.

Q I found the gameplay boring because i had to learn or exercse theseskils.

a I played the garne, but did not conscously link it to AiM.

a The game taught menew stalls:

Q I enjoyed the gameplay regardiess of the sell exeroses required to partochate.

a. pragag the game helped me understand the purpose of AM.

a playng the game helped me better understand how to apply those akdis in other contexts:

D Others

\section{Figure 2: Some of the questions included in the digital questionnaire}




\section{Narrative Overview of Nomad}

Based on a previous encounter with the game's eponymous character, a girl named Ana Kirlitz attempts to discover the mystery behind "The Nomad", tracking her findings on a personal blog. When Ana mysteriously disappears her friend, Mia Schoemaker, attempts to find both Ana and the mysterious Nomad.

Mia does this with the help of students at the University of Pretoria whose classes have been interrupted by mysterious messages from The Nomad. The Nomad's messages lead Mia and the players to the university's library where players must complete tasks such as finding books, decoding ciphers and academic referencing. Completing these tasks provides opportunities for the players to communicate with The Nomad, where they discover that he is a time traveller desperate to return to the present time. Working with The Nomad and Mia, players must race against time itself to free The Nomad, and against the insidious Observer organisation to free Ana from a time prison.

\section{Gameplay Overview of Nomad}

Many puzzles and gameplay tasks were developed for Nomad. However, this article does not highlight or explain every puzzle in an interest on focusing on the learning outcomes reached by the game's core puzzles. As such, this section briefly described the overall flow of the main gameplay and storyline in Nomad.

Nomad opens with a first-year lecture being interrupted by a video transmission from the Nomad, which points students to the game website, which contains a countdown timer (pictured below), and the text "library", to denote a location for players to meet at.

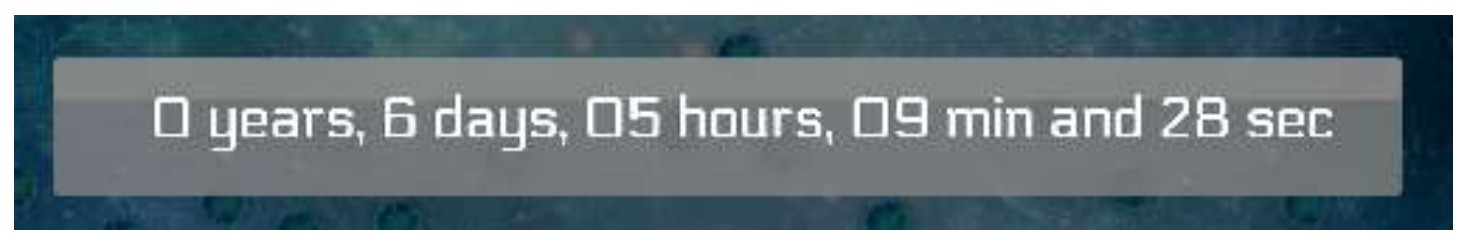

Figure 3: The game website's countdown timer.

Players gather at the library, where they are led into the game's first puzzle as discussed in section 7.1. Once the puzzle is completed they are rewarded with a phone call with The Nomad. This phone call unlocks the second puzzle, detailed in section 7.2.

Upon completing the second puzzle, players participate in an event that has them discover that The Nomad is a time traveller, which in turn unlocks puzzle 3 (see section 7.3), which leads directly onto puzzle 4 (see section 7.4). It was at this point, despite more puzzles having been planned, that Nomad had to end due to time constraints. One example of such a puzzle involved players organising 70 images that contained The Nomad into chronological order in a digital timeline. A completed version of this puzzle is shown below. 


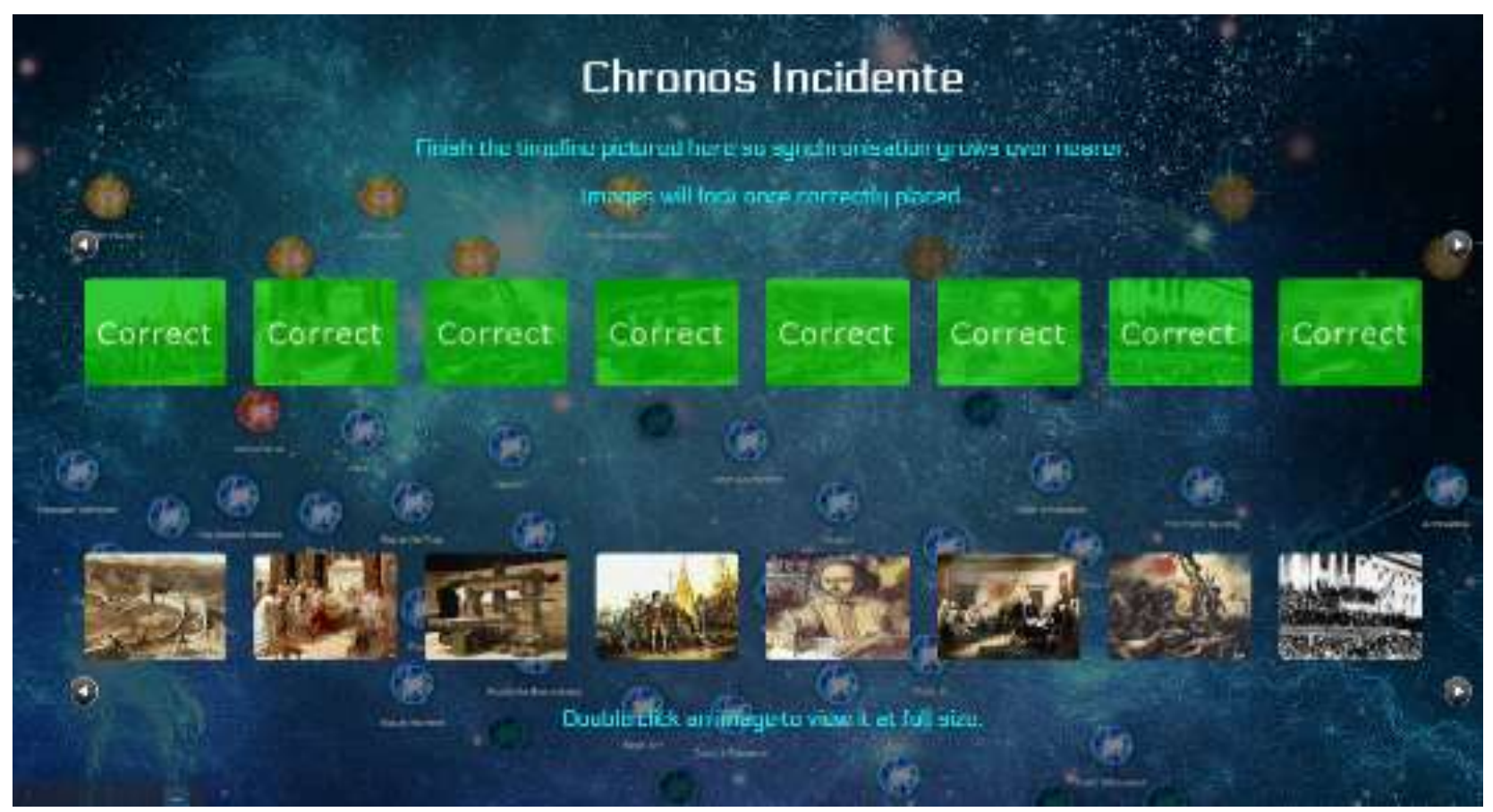

Figure 4: The planned timeline puzzle in Nomad

\section{Sample Game Tasks and Learning Outcomes}

Nomad's primary purpose was to be used as a tool for teaching and exercising 21st century and information literacy skills. In examining this, the following section describes various puzzles in the game, along with which information or digital literacy skills each puzzle attempts to teach or exercise. The below discussion of puzzles is based on work done previously by one of the authors (Jerrett, 2016).

It must be noted here that the puzzles represented below do not represent the entirety of the puzzles in the Nomad ARG. Each of these chosen puzzles were "major" puzzles that required completion in order to finish the ARG as it had been designed.

It must be noted that these puzzle descriptions discuss the design of the puzzles themselves. How players experienced the puzzles within the game context is discussed in section 8.1.

\subsection{Puzzle 1: Finding Books}

Access to books in a physical library is one of the primary functions of libraries. As such, being able to find and access these books is an important skill. As such, Nomad was developed to integrate this core activity into the game. Either a Quick Response (QR) code or a note is placed in each book the players are directed to. QR codes were utilised in the Nomad ARG to link real world assets to sections of the game website by unlocking these sections or providing new information within them. In this puzzle the QR codes, when scanned, lead players to new lists of books that extended the puzzle, whereas dead-end books provided notes that detailed supplementary game narrative. Each book with a QR code inside also unlocks a single letter of a phrase on the game website. This phrase is "N423OXFORD". This phrase is a partial collection number for the Oxford English Dictionary. 


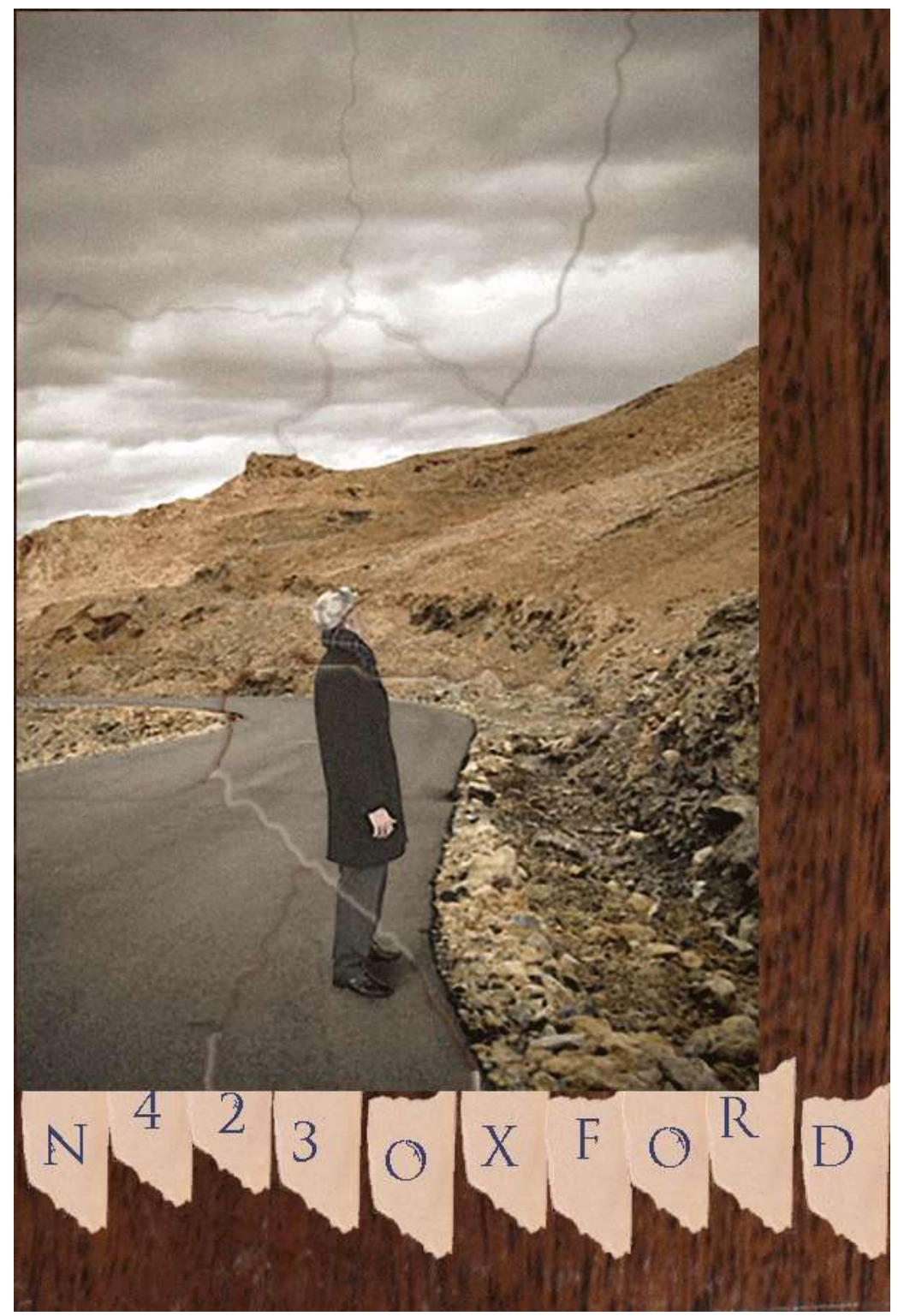

Figure 5: The fully unlocked phrase, with a picture of The Nomad

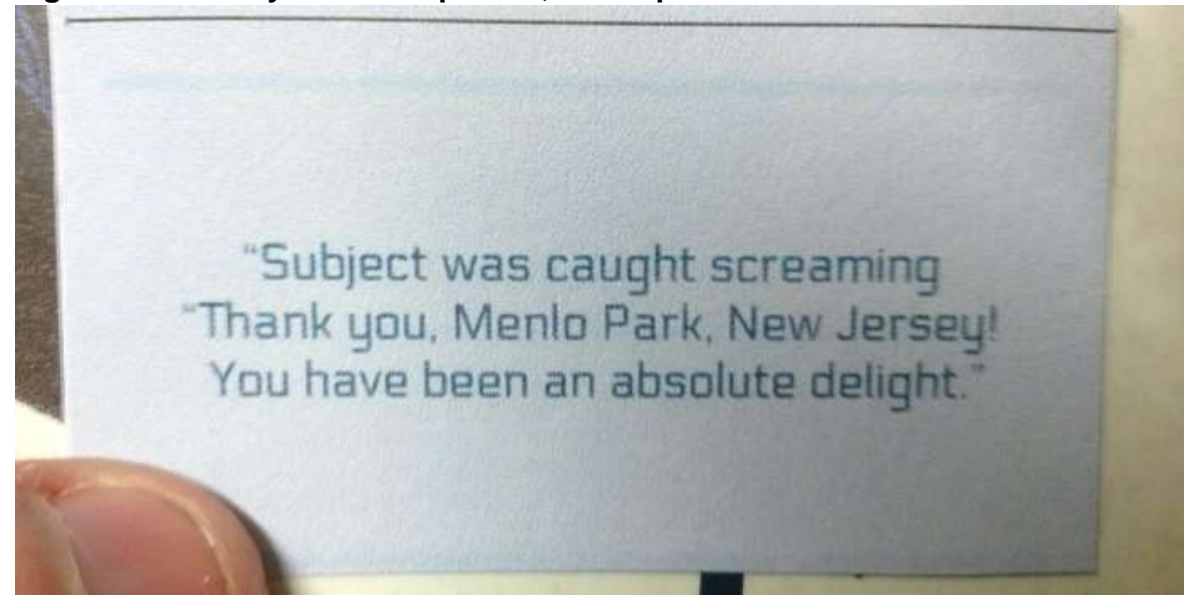

Figure 6: A game narrative "note" in a "dead-end" book 
Players must recognise that this is a collection number in order to find the final book, complete the puzzle and collect the reward: a time, date and location for a rendezvous with The Nomad. Players had one week to complete the puzzle.

In completing these puzzles players learn or exercise the multiple ways to locate books in the library, such as asking library staff for assistance or utilising the library's online portal (Bothma et al., 2014, pp. 47-51). Players find the book by tracking its collection number, which leads them to physical book's location. Once players find the book they must understand how QR codes function in order to unlock the next list of books (Wempen, 2014, p. 57).

Player progression through this puzzle can be seen in Figure 7.

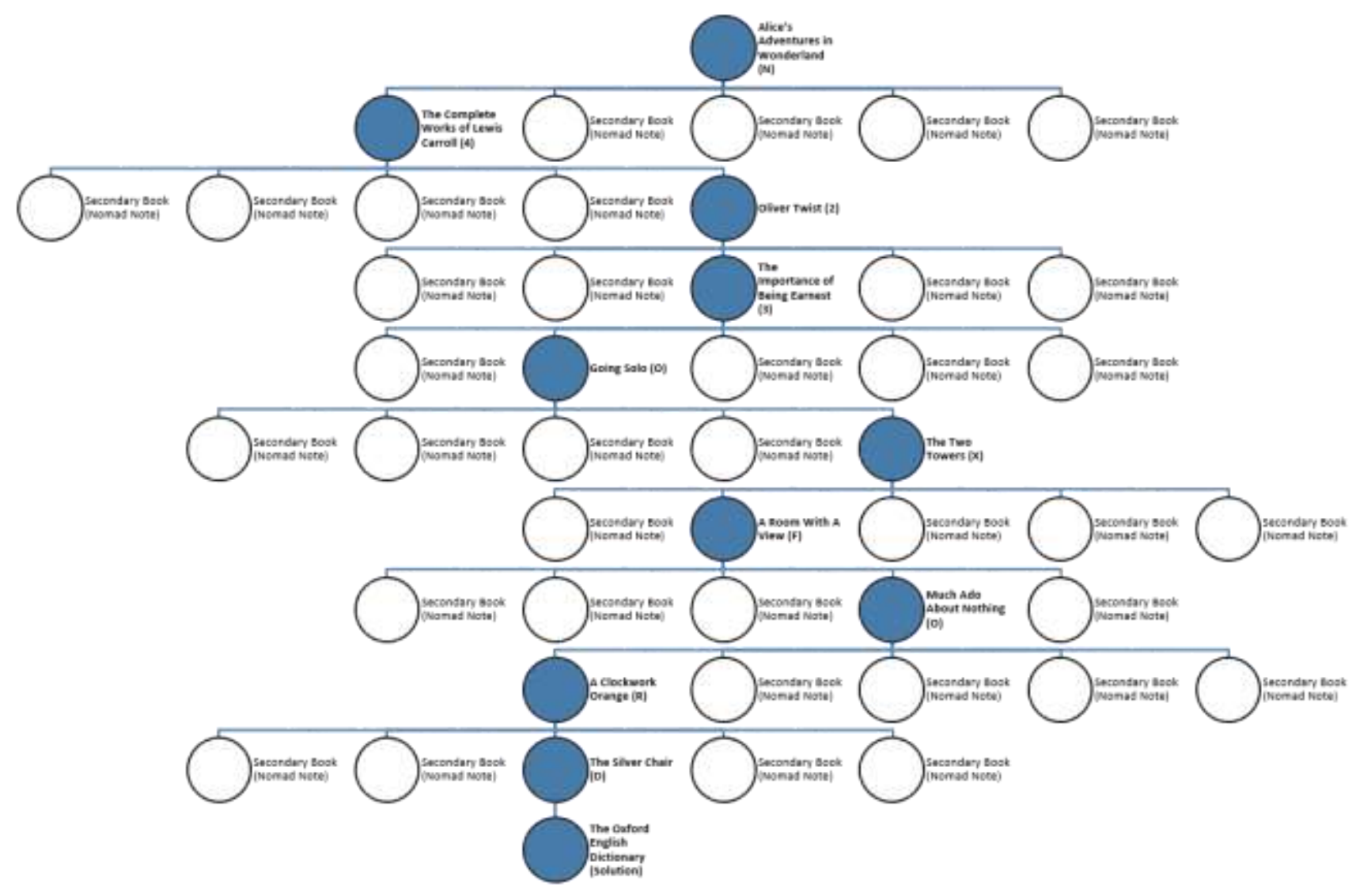

Figure 7: Progression through the game's initial puzzle

Figure 7 showcases player progression through this puzzle. Blue nodes represent books that contained QR codes that continued the puzzle (by presenting players with five new books), whilst white nodes represent books that contained notes that detailed parts of the game narrative (see Figure 6).

As such, the puzzle started by directing players to Alice's Adventures in Wonderland (Carroll, 1865) which unlocked a list of five further books, as well as the first letter of the "N423OXFORD" phrase: the 
letter "N". One of the unlocked books was The Complete Works of Lewis Carroll (Carroll, 1988), which unlocked a letter of the phrase (" 4 ") and another five books. This pattern continues until The Silver Chair (Lewis, 1953), which only provides the final letter of the phrase, "D". Players are then led to The Oxford English Dictionary (Simpson et al., 1989) by linking the full phrase, "N423OXFORD", to the collection number of the book.

\subsection{Puzzle 2: Book Ciphers}

The second major puzzle in Nomad continues having players finding books in the library by first providing them with ISBN numbers that they need to correlate to books on the library's online portal. Similar to the initial puzzle, some of these books contain notes that explain the narrative. Others, however, contain sets of numbers in a specific format. These numbers alluded to page numbers within the book, followed by the first letter of each $n^{\text {th }}$ word on the page (e.g. the number "10" referred to the $10^{\text {th }}$ word on the page). These first letters would subsequently spell out names of further books in the puzzle. Traversal through the books once again rewards players with details of a new event. As before, this event is due to occur a week after the puzzle is allocated to the players.

An example cipher would be "44 - 910841362759566010769 ". An example of this cipher being solved by using The Jungle Book (Kipling, 1894) is shown in Figure 8.

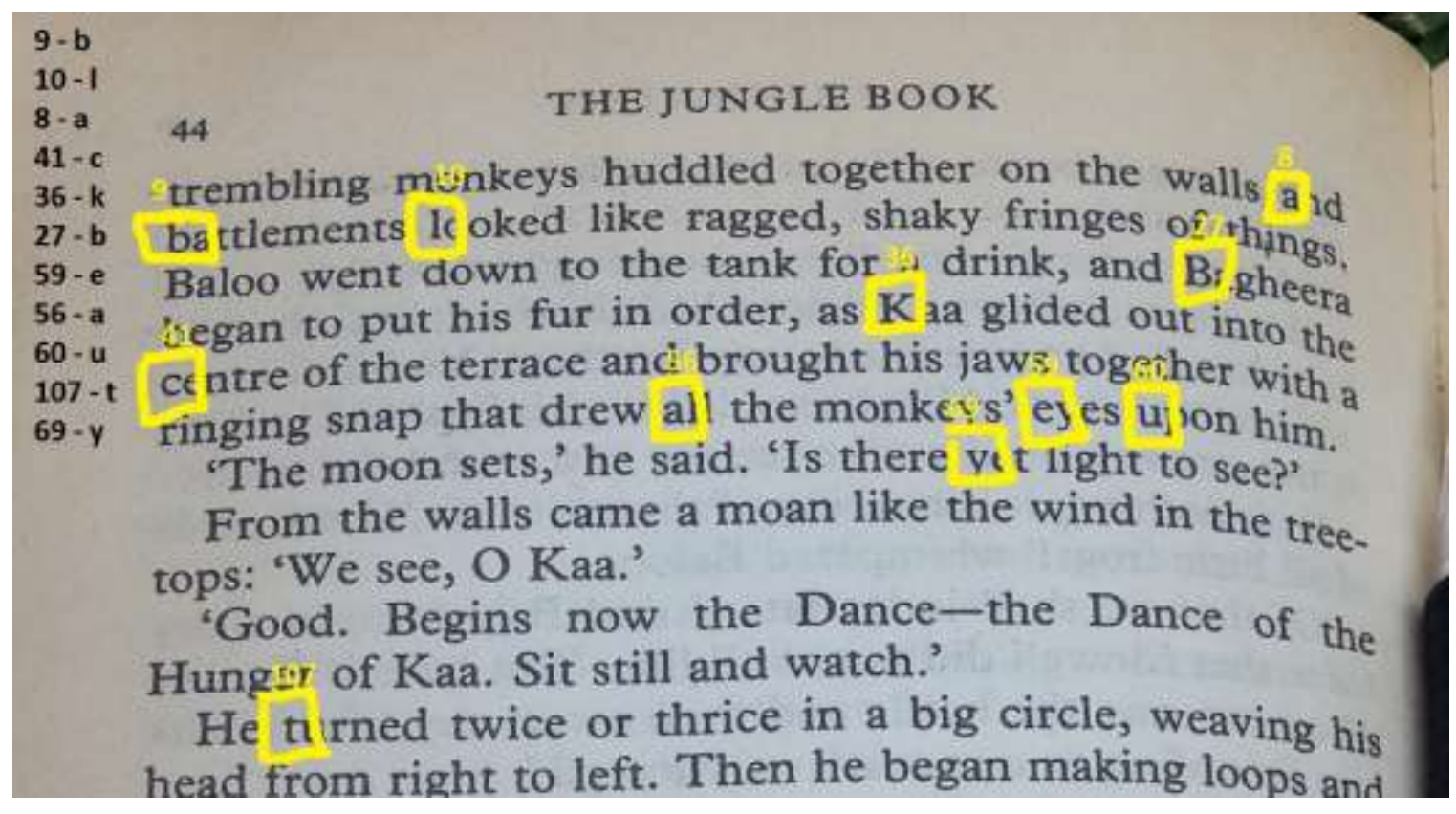

Figure 8: Solving "Black Beauty" with The Jungle Book (Kipling 1894)

This puzzle attempted to increase the complexity of the initial puzzle. This was done by introducing elements of digital literacy that were computer-based (Gilster, 1997, p. 1). The use of cryptography intended to introduce players to its importance in Computer Science-related disciplines, such as computer security (Yang, 2001). For the puzzle to remain library-related, this cryptography is linked to physical books, as players needed to constantly consult the physical books to solve the puzzle. Because 
of this, it was hoped that the players found it necessary to borrow the books from the library to consult the texts at their leisure, thus exercising the skill of library lending (American Library Association and Association for College and Research Libraries, 2000).

The path through this puzzle is showcased in Figure 9.

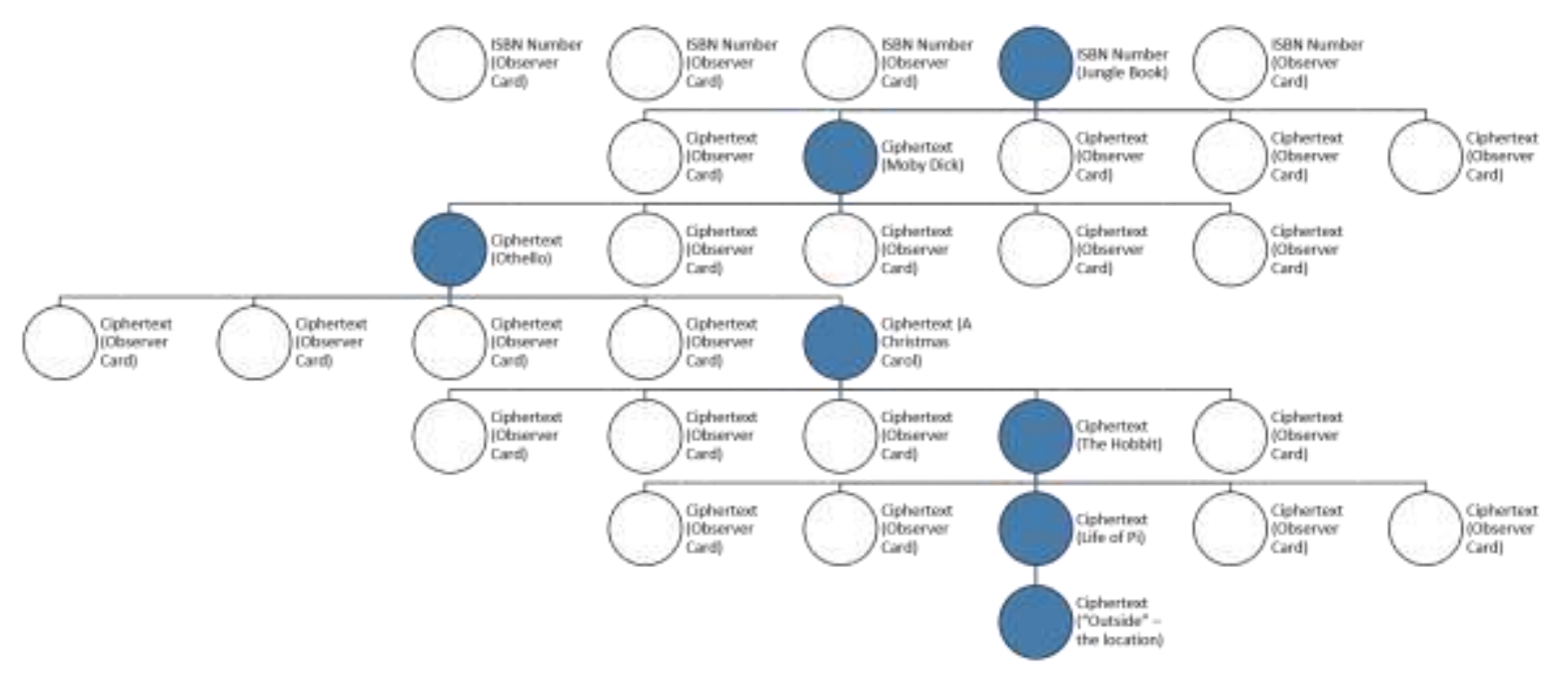

Figure 9: A path through the game's second major puzzle

Similarly to Figure 7, Figure 9 details player progression through the puzzle as a series of blue and white nodes, where blue nodes represent books that extend the puzzle and white nodes contain narrative clues. The puzzle itself spans fewer books than the game's initial puzzle due to the added difficulty of deciphering book titles when provided with ciphertext books (the blue nodes in the figure). Each ciphertext book contained five ciphers that, when decoded, presented five book names, one of which contained another five ciphers. This pattern repeated until the final book of the puzzle, Life of Pi (Martel, 2001), presented a cipher that told players of the event location.

\subsection{Puzzle 3: Solving Riddles, Critical Thinking, Information Dissemination and Collaboration}

The game's next major puzzle involves players solving five riddles that allude to scientific concepts. The below riddle alludes to Morris-Thorne wormholes by referencing famous scientists Mike Morris and Kip Thorne:

Mike and Kip cross an exotic bridge: the year is 1996. Upon making their passage through the calendar reads 1972.

15 players must solve each riddle before the reward is received. As such, this puzzle attempts to introduce the importance of collaboration, a 21st century literacy (Binkley et al., 2012), in ARGs to the players (Bonsignore et al., 2012). Players are encouraged to share the answers to each riddle as they are solved as well as to individually solve each of the five riddles so that the players can progress in the 
game. This teaches the players critical thinking (in order to solve the riddles), as well as information dissemination and collaboration in groups (Bonsignore et al., 2012).

\subsection{Puzzle 4: Referencing - Completing The Nomad's Research}

Completing the riddles in the previous puzzle rewards players with a note from a game character discussing The Nomad's unfinished research. The note informs the players that the answers to the five riddles were The Nomad's areas of expertise, and that perhaps finding relevant articles within these fields may help with The Nomad's rescue. In this regard, the players are presented with a web form that matches input text to a pattern that matches the University of Pretoria's Harvard method of referencing (Bothma et al. 2014, p. 141). Players must find names of articles and format them as a bibliographic reference in order to have the form accept their submission. Once an adequate number of article names were submitted for each topic the players were rewarded.

Due to the progression driven nature of this puzzle, along with the puzzle detailed in section 6.3 , there was no strict time limit on these two puzzles, though it was hoped that players would complete this puzzle within two weeks of it being presented to them.

The pattern players had to match explicitly focused on journal articles, and as such accepted references in the following general format:

Surname, Initials. Year. Article name. Journal name, Volume(Issue): Page range start-Page range end

As such, it accepts the following reference, as shown in Table 1.

Table 1: A breakdown of the pattern format that was accepted in the puzzle

\begin{tabular}{|l|l|l|l|l|l|l|l|l|}
\hline Surname & Initials & Year & Article name & Journal Name & Volume & Issue & $\begin{array}{l}\text { Page } \\
\text { range } \\
\text { start }\end{array}$ & $\begin{array}{l}\text { Page range } \\
\text { end }\end{array}$ \\
\hline Richardson & G.P & 1986 & $\begin{array}{l}\text { Problems with } \\
\text { causal loop } \\
\text { diagrams }\end{array}$ & $\begin{array}{l}\text { System Dynamics } \\
\text { Review }\end{array}$ & 2 & 2 & 158 & 170 \\
\hline
\end{tabular}




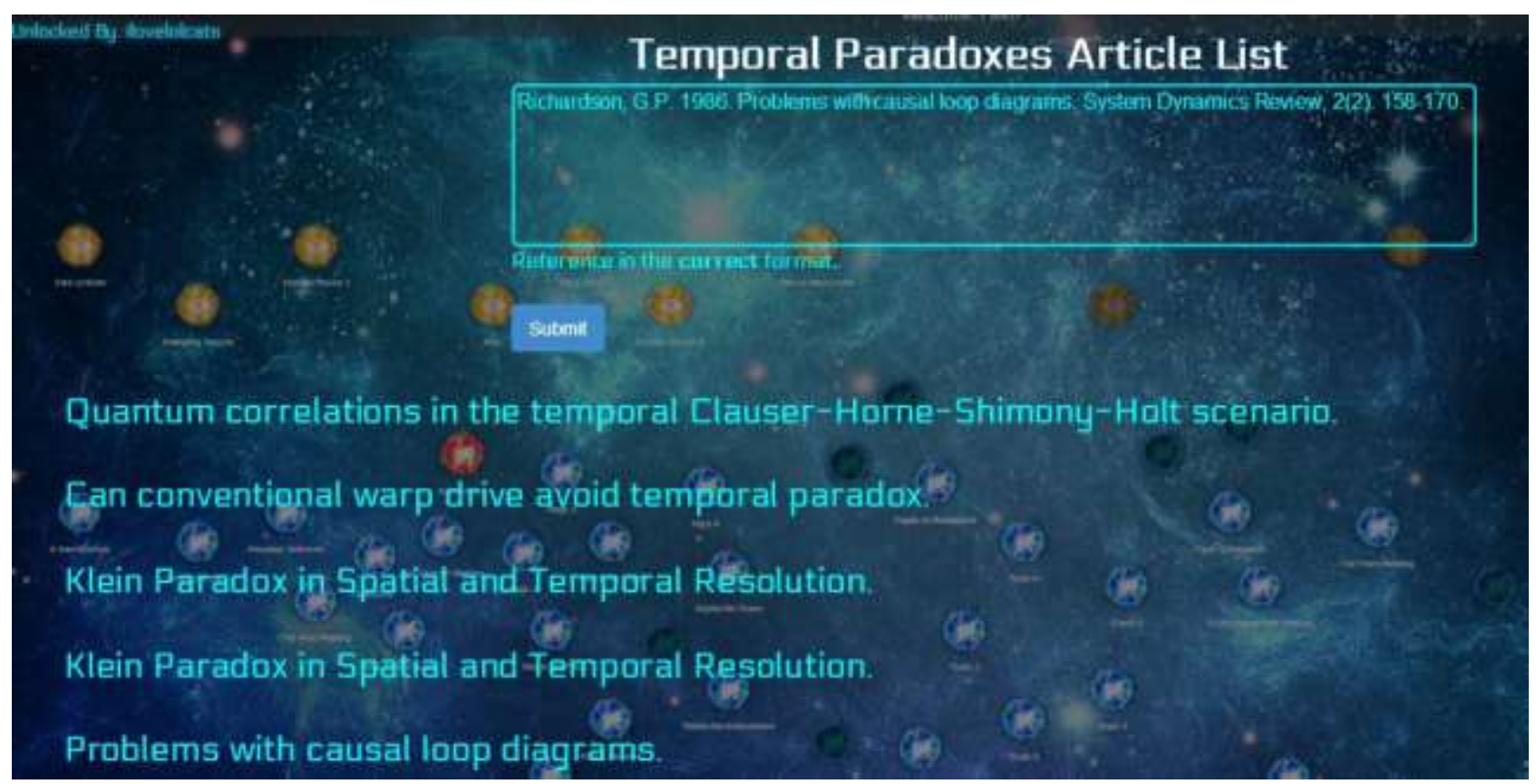

Figure 10: An example of correct player input during this puzzle

Players were required to use a variety of online research portals, library services and web searches to find relevant journal articles on the given topics. This puzzle hoped to introduce players to the online resources and databases provided by the University of Pretoria library through the university's subscription to these databases, such as ScienceDirect, EBSCOHost, Gartner and other databases articles (Bothma et al. 2014, pp. 48-51). In utilising these resources, players would learn the difference between these resources as well as how to complete goals (such as finding articles) using these platforms (Bothma et al. 2014, pp. 84-91).

\section{Findings}

Data gathering in the study was largely qualitative, consisting of researcher observation, as well as participant focus group interviews and questionnaires. Researcher observation was augmented by document analysis of the game websites, as well as web analytics (wherein quantitative data helped support qualitative inferences).

Data from these sources was then subjected to constant comparative analysis (Pickard, 2013, p. 269; Strauss and Corbin, 1998, p. 67). Constant comparative analysis is a multi-phased coding process that recursively identifies themes and categories within data sets and refining them until inferences can be made (Strauss \& Corbin, 1998, p. 13).

Findings regarded participant use of the university library throughout the game, as well as the degree of skill acquisition and exercise players felt throughout the play of the game. The focus groups and questionnaires also allowed players to discuss their enjoyment of the ARG as a game-based learning tool.

However, due to the size of these focus groups, the findings presented within this section are exclusive to the Nomad ARG, and are not generalisable. Despite this, lessons learned from the Nomad ARG may be useful to future researchers. 


\subsection{How The Players Played Nomad}

Players rapidly completed the first puzzle (illustrated in Figure 7), completing it in two days, despite being allocated a week to complete it. This showcases the fervour of the players at the start of the game. The speedy completion of this puzzle also suggests that players were already aware of how to utilise and find their way around the university library, including how to use the university's online library portal. This indicates that players had a high level of information and library literacy at the start of play. This proved a successful baseline for what the designers could expect of the player group going forward.

However, play slowed as the game continued. The second major puzzle tasked players with decoding ciphers hidden within various books to reveal the name of other books. Players got stuck here, struggling to understand how to decode the ciphers from the cryptic information given: a book and a string of numbers. Despite initially pouring over the puzzle in an effort to solve it, frustration and boredom took root and players moved on to other game-related tasks instead. Eventually, the puzzle was abandoned and the game moved onto the next puzzle. Notably, during their attempts to decode the ciphers, players would borrow the necessary books from the library to attempt decoding at their leisure. This proves that, at least, the puzzle exercised this library literacy skill (library lending).

Play of the game then progressed smoothly, with players quickly solving the game's riddle solving puzzle (detailed in section 7.3), indicating a well-designed puzzle at the expected difficulty level. Completing this puzzle unlocked another puzzle that required players to find and reference scientific journal articles in order to, narratively, complete The Nomad's research. It was here that play stalled once again, with initial confusion regarding the correct format for references to be input into the automated system, which checked the reference against a regular expression to determine correctness. Here, the puzzle designed seemed to fail again, being slightly too obscure and thus losing player engagement.

At this point in the game, the allocated time for play (six weeks) had almost elapsed. As a result, the game had to be ended prematurely, despite the players having not solved this puzzle. An alternate ending to the game that correlated to the amount of the game that had been completed (about 65\%) was written and performed to provide players with some narrative closure.

Despite a failure to complete the game in the allotted time, the players of Nomad remained engaged with the game content (though less so with some specific puzzles). Players reportedly self-organised meetings at the library to discover and catch up on game content, and kept fairly active on player forums and instant messaging groups during gameplay. Such engagement is typified by one player sprinting across the university campus during the game's final event.

\subsection{Linking Game Goals to Learning Outcomes}

Both the questionnaire and the focus groups were examined considering how Nomad, as a game, taught its player community various skills and 21st century literacies.

When asked about the educational components of Nomad, players noted that they did not consciously link Nomad to the compulsory credit-bearing information literacy modules discussed earlier (see Section 1). However, they collectively noticed that the game was educational when the primary game location (the library) and game puzzles (finding books) were repeated. One player, however, reported being 
unaware of this, stating that she was unaware of the link until "[her significant other] told [her] 'Can't you see it's teaching you how to use the library?"'

However, the players did not find that the educational components of Nomad made the game less engaging, noting through the questionnaire that they enjoyed the game regardless of the skills that needed to be exercised during play, with one player noting "when you're playing a game, you're focused on play, not learning". This is important in disproving the stigma that educational games should not also be fun (Abt, 1987, p. 9; Michael and Chen, 2005, p. 17). This demonstrates that the most effective way to teach through games is tangentially: players learn through play, but the experience of play remains paramount. Another player noted that the "educational bits were well hidden by the story".

When asked specifically about the game's relation to library literacy tasks during the focus group, players praised the ludic framing that Nomad gave to these traditional tasks, noting that it made the tasks more engaging. One player noted that the tasks were "very motivational. You had to find the books, but there was a reason for it. Usually you have to find the motivation to do these things." Another player noted that "it's better to learn these things now rather than next year when I fail [because I don't know how to do them]".

Players also noted that the game helped them contextualise 21st century literacy skills and how to apply these skills in external contexts more effectively. They also felt that Nomad could be an effective practical component to complement modules that teach 21st century literacies.

As such, it would seem that Nomad was effective in linking its game goals to the intended learning outcomes of the study (to teach 21st century literacies) whilst providing an engaging experience. Players noted that they would play similar games in the future if provided the opportunity.

\subsection{Skill Exercise and Acquisition}

The questionnaire for Nomad specifically focused on the 21st century literacies and skills that players felt they learnt during play. The questionnaire suggested 14 skills to players. Collectively (through an aggregation of all questionnaire responses) the players felt that all the available skills noted within the questionnaire were taught during gameplay. The skills suggested in the questionnaire are listed in Table

The skills players self-reported they had learnt or exercised is corroborated below by referring to how the game taught or exercised that skill, as well as the observed occurrences of this skill exercise by the researchers during gameplay.

It is important to note here that the format of the questionnaire did not allow for players to discuss how they felt specific skills were taught. However, if players made mention of a point at which they used a skill in the focus group, it is included. 
Table 2: Skills taught and exercised in Nomad

\begin{tabular}{|c|c|}
\hline Skill taught/exercised & Puzzle that taught/exercised this skill \\
\hline Searching for books in a library & $\begin{array}{l}\text { The game's first two major puzzles revolved } \\
\text { around finding books in the library. Players } \\
\text { noted that they spent a lot of time in the } \\
\text { library, and that they knew the game was based } \\
\text { around it. }\end{array}$ \\
\hline Understanding and decoding ciphers & $\begin{array}{l}\text { The game's second major puzzle tasked players } \\
\text { with cipher decoding. Players noted being } \\
\text { frustrated and confused by this puzzle's } \\
\text { ciphers. }\end{array}$ \\
\hline Academic referencing & $\begin{array}{l}\text { The game's fourth major puzzle tasked players } \\
\text { with creating a reference library/bibliography } \\
\text { for The Nomad's work. Players found this } \\
\text { puzzle dull and "too obvious" as a skill teaching } \\
\text { exercise. }\end{array}$ \\
\hline Internet search query construction & $\begin{array}{l}\text { The riddle puzzles often required critical } \\
\text { thinking as well as search query construction. } \\
\text { Additionally, making sense of the notes found } \\
\text { in books in the game's first two puzzles } \\
\text { required careful query construction to } \\
\text { contextualise. }\end{array}$ \\
\hline Searching the internet & $\begin{array}{l}\text { As noted above, riddle solving and general } \\
\text { narrative contextualisation required this. }\end{array}$ \\
\hline $\begin{array}{l}\text { Using academic journal databases to search for } \\
\text { articles }\end{array}$ & $\begin{array}{l}\text { The game's fourth primary puzzle revolved } \\
\text { around searching academic sources in order to } \\
\text { create The Nomad's reference } \\
\text { library/bibliography. Players did not enjoy this } \\
\text { puzzle, as noted previously. }\end{array}$ \\
\hline Using the University Library Portal & $\begin{array}{l}\text { Players had to use the library portal to find } \\
\text { collection numbers for books in the game's first } \\
\text { two major puzzles. }\end{array}$ \\
\hline $\begin{array}{l}\text { Using different technological platforms (mobile, } \\
\text { PC) }\end{array}$ & $\begin{array}{l}\text { The use of multiple platforms in Nomad was } \\
\text { facilitated by having mobile and desktop } \\
\text { versions of game websites. }\end{array}$ \\
\hline $\begin{array}{l}\text { Communication with a community through } \\
\text { social media }\end{array}$ & $\begin{array}{l}\text { Players communicated with other players } \\
\text { through the use of social media and instant } \\
\text { messaging services. Players also set up their } \\
\text { own private forum "so that [the game }\end{array}$ \\
\hline
\end{tabular}




\begin{tabular}{|c|c|}
\hline & $\begin{array}{l}\text { designers couldn't] see what [they were] } \\
\text { planning". }\end{array}$ \\
\hline Using internet blogs, forums and social media & $\begin{array}{l}\text { The use of internet blogs and forums was } \\
\text { necessary during play due to the nature of the } \\
\text { game websites (a blog and a forum). As noted, } \\
\text { player communication was often done through } \\
\text { social media. }\end{array}$ \\
\hline Group problem solving & $\begin{array}{l}\text { Collaborative problem solving could be seen in } \\
\text { most puzzles (the notes in the books in the first } \\
\text { two major puzzles, solving the riddles and other } \\
\text { puzzles not described in this article). Players } \\
\text { specifically noted the riddle puzzle ( } 7.3 \text { ) as a } \\
\text { collaborative effort, saying that they all sat } \\
\text { down together at a coffee shop on campus to } \\
\text { solve the puzzle. }\end{array}$ \\
\hline Evaluating the relevance of information & $\begin{array}{l}\text { Most information in an ARG, such as the } \\
\text { information on the notes in the first major } \\
\text { puzzles, must be evaluated in order to } \\
\text { contextualise how they related to the game's } \\
\text { narrative. Additionally, players must also } \\
\text { contextualise information within reality as } \\
\text { internal or external to the game itself. The } \\
\text { players shared a collaborative cloud folder to } \\
\text { put all their game findings in: specifically, this } \\
\text { folder was used for uploading pictures of the } \\
\text { notes found in the first two major puzzles. }\end{array}$ \\
\hline Rearranging information to provide context & $\begin{array}{l}\text { Like the contextualisation of information } \\
\text { relevance mentioned above, context gleaned } \\
\text { from rearranging information could also be } \\
\text { exercised through the discovery of notes within } \\
\text { the game puzzles. }\end{array}$ \\
\hline Exploratory or tangential learning & $\begin{array}{l}\text { Though ARGs are, by their nature, exploratory, } \\
\text { various aspects of the game allow for tangential } \\
\text { learning, such as players reading a specific book } \\
\text { the game's first puzzles pointed them to in } \\
\text { order to discover whether the text had any } \\
\text { relevant information that they could use in- } \\
\text { game. }\end{array}$ \\
\hline
\end{tabular}

Players also noted that Nomad taught them an array of other 21st century skills. These included, among others, the following: 
- How to view HTML source code within a browser ("I didn't know how to access the code of a website before").

- The different functionalities of Skype as an instant messaging and VoIP (Voice-Over-IP) client (“I had never used Skype before").

- How to use the library and its computers for finding resources and books ("I can use the library now!").

The players also noted that Nomad's use of the campus as the play space could be useful for orientation purposes for new students. One player suggested "it would be really cool to do one of these for [orientation week] in the [residences]", echoing the usefulness of orientation-based ARGs like ViolaQuest (Whitton, 2009) and Who is Herring Hale? (Piatt, 2009).

\subsection{Shortcomings in Nomad's Implementation}

Despite the success of Nomad as an entertaining educational game, there were multiple shortcomings in the game's implementation as expressed by players and observed by the researchers. Some of these include:

- Elements of the game were repetitive, such as the continued location of books. This repetition aimed to increase community size and work division. However, because players played primarily as a group, work division was not performed and the repetition became boring.

- The game websites, as a result of slow servers and poor integration, often had long access times, which frustrated players.

- The use of phone calls as a medium of instruction was often confusing due to poor line quality.

- For transparency and clarity, the game timeline should have been provided to players, giving deadlines for the completion of puzzles in order to motivate play.

- Some game puzzles (specifically the reference puzzle described in section 7.4) did not fit into the game narrative as well as previous puzzles. These puzzles were reported by the players as boring as a result.

- Diversify locations, such as the library, in order to vary gameplay.

These shortcomings, along with other observed considerations, are analysed in the following section in an attempt to provide general guidelines for both educational ARG design and information literacy specific ARG design to future game designers.

\section{Considerations for Future Research and Implementation}

Nomad provides myriad considerations for future educational ARG designers when designing both information literacy ARGs and other ARGs. These considerations are discussed below.

\subsection{Diversify the Game's Locations and Tasks}

Educational games need to meet learning outcomes. Because of this it is tempting to design them as educational vehicles that repeat locations, skills and activities in order to promote their in-game exercise. It is advisable, however, to alternate these learning outcome tasks with tangential educational tasks, or tasks that are more entertaining than educational. This change of pace may make players more forgiving of the tasks that are geared more specifically towards learning outcomes when they must be completed during gameplay. 


\subsection{Attempt to Host Web-based Content Locally}

ARGs with many web-based components are tempting to create as these components can be changed remotely at any point during the game (as opposed to the often more-difficult replacement of physical assets). However, technical issues can hinder the effectiveness of such components. As a result, any online asset in an ARG should be quickly accessible and well-integrated with existing systems to minimise any break in immersion as a result of technical difficulties.

\subsection{Design for Transparency in Educational ARGs}

The design aesthetic of "this is not a game" is tempting in ARGs due to the increased authenticity and immersion it provides (see section 3.2.1). However, it may not be as useful in educational applications in favour of in-game transparency. This transparency includes providing players with deadlines, allowing them to see and understand the overall game structure, and potentially having either in-game or external assistance. This also means that instructions should be clear and unambiguous in order to promote less frustration during task completion.

In Section 6, designed time limit suggestions were discussed for various puzzles. However, these time limits were never explicitly communicated to the players (as the nature of an ARG allowed the designers to move around event dates based on player progress). However, Nomad needed to be completed within six weeks to avoid interfering with the players' examination period. This upper limit was not communicated to the players, and was a major flaw in Nomad's design.

\subsection{Design for Simplicity and Linearity}

While part of the allure of the ARG genre is the ability of players to change the game, presenting an ARG as a guided educational experience is not an incorrect design decision. One can design for player autonomy while presenting an otherwise linear experience, as long as player autonomy puzzle/story branches converge back to the main story. This has the benefit of providing minor changes to the story based on player action whilst keeping the amount of simultaneous game puzzles presented to the players low. As a result, players can focus on one game element at a time, minimising the risk of information overload.

\subsection{Promote Large Communities, but Do Not Require Them by Design}

Nomad joins ARGs such as Who Is Herring Hale? (Piatt, 2009) and ViolaQuest (Whitton, 2009) in reiterating that ARGs will likely be played and enjoyed by players who have a predisposition towards games. As a result, voluntary, small scale, educational ARGs will likely not be played by incredibly large groups, regardless of sampling methods. As such, it is best to design ARGs to support and reward community recruitment without explicitly requiring large communities for game puzzles.

\subsection{Consider an Action Research Approach to Educational ARG Design}

Many educational ARGs are presented as case studies that report qualitative results noting that ARGs are useful educational tools due to their entertainment value as well as their educational potential (Bonsignore et al., 2013; Connolly et al., 2011; Fujimoto, 2012; Hakulinen, 2013; Niemeyer et al., 2009; Piatt, 2009; Whitton, 2009). However, there is often a lack of objective testing following gameplay to confirm skill exercise and acquisition within these applications. Players are assumed to have learnt the skill due to their completion of the ARG and self-reported feedback. Future researchers may consider 
designing ARGs as interventions within an action research approach to make use of objective postintervention evaluation methods. This could also be useful in order to compare members of the target audience who played the ARG to those who did not in order to examine whether the ARG objectively improve the skills of those who played.

\subsection{Consider an ARG's Running Time}

Nomad ran for six weeks, but experienced multiple slow periods where little play occurred. BiblioBouts, the online information literacy game discussed earlier, presents a similar long gameplay experience, lasting an entire semester (Markey et al., 2014). Nomad's players expressed similar sentiments to Bibliobouts players regarding the length of the game when play slowed due to external responsibilities. Nomad's players became demotivated as the game timeline continued despite these responsibilities, leading to in-game consequences (such as final warnings that The Nomad would be lost forever if they did not solve puzzles in a timely manner). However, unlike BiblioBouts, the six week running time for Nomad was, if anything, too short for the amount of developed content. As such, finding the correct content to running time ratio is imperative for educational ARGs.

One must consider the ramifications of long ARGs in this regard, however, as longer running times and periods of slowdown may result in players losing interest. The development of short educational ARGs (such as week-long games) in order to maintain engagement is a promising area of future research, though it is imperative that players have few external responsibilities during these short running periods as missing content in shorter applications may be severely detrimental to both the learning and overall player experience.

\section{Final Thoughts}

Alternate reality games as a genre are useful vehicles for teaching $21^{\text {st }}$ century literacies (Bonsignore et al., 2012). As such, marrying a genre proficient at literacy skill exercise with game design targeted towards explicitly teaching and exercising literacies seemed to be a logical choice.

Nomad was the product of that marriage. The discussion of Nomad's major puzzles within this article hopes to inspire future designers to utilise aspects of Nomad's puzzle design and literacy teaching approach in the application of future games, whilst keeping in mind the considerations for future educational ARGs as noted above.

This article sought to discuss the usefulness of a designed ARG for teaching $21^{\text {st }}$ century literacies. In doing so, Nomad was examined as a non-violent, co-operative game that was played in the real world.

Designing Nomad in this way presented players with a game about affecting positive change, like Urgent: Evoke (Waddington, 2013) and World Without Oil (Rusnak et al., 2008) before it. The utilisation of Malone and Lepper's (1987) intrinsic motivations helped create a compelling game world within the real world.

This link to the real world allowed the game to be more contextually relevant to the players, and teach them through a direct mapping of game actions to real-world skills (Lee, 2006; McGonigal, 2003b). This increased engagement and retention with the core educational content (Koestner et al., 2008).

Most importantly, Nomad was enjoyed by its players as both a game and as an educational product. Despite shortfalls in the implementation, the overall positive outcome regarding the player experience 
of Nomad suggests that Nomad was a successful educational application, that alternate reality games are a viable genre for educational applications, and that well-received elements within Nomad could inspire other educational ARGs to engage in similar design practices.

Overall, it is hoped that the case study of Nomad, as it is presented in this article, showcases ways in which to create entertaining, effective educational ARGs and, in doing so, helps dispel the stigma surrounding educational games, whether digital or real-world, as "chocolate covered broccoli" (Laurel, 2001). In doing so, educational ARGs can find inspiration in the ARG genre's mantra: "this is not a game, you are not playing". Instead, however, it might be apt to change it to "this might be a game, but you are still learning".

\section{References}

Abt, C.C. (1987), Serious Games, 2nd ed., University Press of America, New York.

Alternate Reality Gaming Network. (2002), "What Is An ARG?”, available at:

http://www.argn.com/what.html (accessed 11 June 2015).

American Library Association and Association for College and Research Libraries. (2000), "Information Literacy Competency Standards for Higher Education", available at: http://arizona.openrepository.com/arizona/handle/10150/105645 (accessed 19 January 2016).

Badke, W.B. (2005), “Can’t Get No Respect: Helping Faculty to Understand the Educational Power of Information Literacy", The Reference Librarian, Vol. 43 No. 89-90, pp. 63-80.

Battles, J. (2014), "Beyond the Board: Alternate Reality Games in Libraries", in Kirsch, B.A. (Ed.), Games in Libraries: Essays on Using Play to Connect and Instruct, McFarland, North Carolina, pp. 187202.

Battles, J., Glenn, V. and Shedd, L. (2011), “Rethinking the Library Game: Creating an Alternate Reality with Social Media", Journal of Web Librarianship, Vol. 5 No. 2, pp. 114-131.

de Beer, K. and Holmner, M. (2013), "The Design of an Alternate reality Game as a Capstone Course in the Multimedia Post-Graduate Degree", Proceedings of the IATUL Conference 2013, Cape Town, available at: http://docs.lib.purdue.edu/iatul/2013/papers/30 (accessed 19 February 2015).

de Boer, A.L., Bothma, T. and du Toit, P. (2011), "Enhancing information literacy through the application of Whole Brain strategies", Libri, Vol. 61 No. 1, pp. 67-75. 
Bono, J.J. and Breeze, M. (2008), "What is an ARG? : ARGology", available at:

http://www.argology.org/_what-is-an-arg/(accessed 16 September 2014).

Bonsignore, E., Hansen, D., Kraus, K. and Ruppel, M. (2012), “Alternate Reality Games as Platforms for Practicing 21st-Century Literacies", International Journal of Learning and Media, Vol. 4 No. 1, pp. 25-54.

Bonsignore, E., Hansen, D., Kraus, K., Visconti, A., Ahn, J. and Druin, A. (2013), "Playing for Real:

Designing Alternate Reality Games for Teenagers in Learning Contexts", Proceedings of the 12th International Conference on Interaction Design and Children, ACM, New York, pp. 237-246.

Bothma, T., Cosijn, E., Fourie, I. and Penzhorn, C. (2014), Navigating Information Literacy: Your Information Society Survival Toolkit, 2nd ed., Pearson South Africa, Cape Town.

Broussard, M.J.S. (2012), “Digital games in academic libraries: a review of games and suggested best practices", Reference Services Review, Vol. 40 No. 1, pp. 75-89.

Carroll, L. (1865), Alice's Adventures in Wonderland, 1st ed., BiblioBytes, Hoboken, available at: http://search.ebscohost.com/login.aspx?direct=true\&scope=site \&db=nlebk\&db=nlabk\&AN=200 8439 (accessed 6 August 2015).

Carroll, L. (1988), The Complete Works of Lewis Carroll, 1st ed., Penguin, London.

Cazden, C., Cope, B., Fairclough, N., Gee, J., Kalantzis, M., Kress, G., Luke, A., et al. (1996), “A pedagogy of multiliteracies: Designing social futures", Harvard Educational Review, Vol. 66 No. 1, pp. 6092.

Chess, S. and Booth, P. (2013), "Lessons down a rabbit hole: Alternate reality gaming in the classroom", New Media \& Society, available at:https://doi.org/10.1177/1461444813497554.

Connolly, T.M., Stansfield, M. and Hainey, T. (2011), "An alternate reality game for language learning: ARGuing for multilingual motivation", Computers \& Education, Vol. 57 No. 1, pp. 1389-1415. 
Dena, C. (2008), “Emerging Participatory Culture Practices Player-Created Tiers in Alternate Reality Games", Convergence: The International Journal of Research into New Media Technologies, Vol. 14 No. 1, pp. 41-57.

Dickey, M.D. (2006), “'Ninja Looting' for Instructional Design: The Design Challenges of Creating a Gamebased Learning Environment", ACM SIGGRAPH 2006 Educators Program, ACM, New York, available at:https://doi.org/10.1145/1179295.1179313.

Donald, J. (2008), “The ‘Blood on the Stacks' ARG: Immersive Marketing Meets Library New Student Orientation", in Harris, A. and Rice, S.E. (Eds.), Gaming in Academic Libraries: Collections, Marketing and Information Literacy, Association of College and Research Libraries, Chicago, available at: http://digitalcommons.trinity.edu/lib_faculty/46.

Fujimoto, R. (2012), “Designing An Educational Alternate Reality Game”, available at: http://www.shoyu.com/education/Research_DesigningAnEducationalARG.pdf (accessed 14 May 2014).

Galarneau, L. (2005), “Authentic learning experiences through play: Games, simulations and the construction of knowledge", 29 May, available at: http://summit.sfu.ca/item/245 (accessed 24 March 2014).

Gee, J.P. (2003), "What video games have to teach us about learning and literacy", Computers in Entertainment, Vol. 1 No. 1, pp. 1-3.

Gentile, D.A. and Gentile, J.R. (2007), “Violent Video Games as Exemplary Teachers: A Conceptual Analysis", Journal of Youth and Adolescence, Vol. 37 No. 2, pp. 127-141.

Gerring, J. (2004), "What is a case study and what is it good for?", American Political Science Review, Vol. 98 No. 2, pp. 341-354.

Gilster, P. (1997), Digital Literacy, 1st ed., John Wiley \& Sons, New York. 
Gorman, G.E., Clayton, P.R., Shep, S.J. and Clayton, A. (2005), Qualitative Research for the Information Professional: A Practical Handbook, 1st ed., Facet, London.

Granic, I., Lobel, A. and Engels, R.C. (2014), "The benefits of playing video games", American Psychologist, Vol. 69 No. 1, pp. 66-78.

Gurzick, D., White, K.F., Lutters, W.G., Landry, B.M., Dombrowski, C. and Kim, J.Y. (2011), “Designing the Future of Collaborative Workplace Systems: Lessons Learned from a Comparison with Alternate Reality Games", Proceedings of the 2011 iConference, ACM, New York, pp. 174-180.

Hakulinen, L. (2013), "Alternate Reality Games for Computer Science Education", Proceedings of the 13th Koli Calling International Conference on Computing Education Research, ACM, New York, pp. 43-50.

Hansen, D., Bonsignore, E., Ruppel, M., Visconti, A. and Kraus, K. (2013), “Designing Reusable Alternate Reality Games", Proceedings of the SIGCHI Conference on Human Factors in Computing Systems, ACM, New York, pp. 1529-1538.

Hsu, C.-L. and Lu, H.-P. (2007), “Consumer Behavior in Online Game Communities: A Motivational Factor Perspective", Computers in Human Behavior, Vol. 23 No. 3, pp. 1642-1659.

Ines, D.L. and Abdelkader, G. (2011), "Facebook Games: Between Social and Personal Aspects", International Journal of Computer Information Systems and Industrial Management Applications, Vol. 3, pp. 713-723.

Jerrett, A. (2016), Using an Alternate Reality Game to Teach Information Literacy, Masters Dissertation, University of Pretoria, Pretoria, available at: http://repository.up.ac.za/handle/2263/57484 (accessed 26 April 2016).

Johnston, J.D., Massey, A.P. and Marker-Hoffman, R.L. (2012), “Using an Alternate Reality Game to Increase Physical Activity and Decrease Obesity Risk of College Students", Journal of Diabetes Science and Technology, Vol. 6 No. 4, pp. 828-838. 
Kim, J.Y., Allen, J.P. and Lee, E. (2008), "Alternate reality gaming", Communications of the ACM, Vol. 51 No. 2, pp. 36-42.

Kipling, R. (1894), The Jungle Book, 1st ed., Macmillan, United Kingdom.

Koestner, R., Otis, N., Powers, T.A., Pelletier, L. and Gagnon, H. (2008), “Autonomous Motivation, Controlled Motivation, and Goal Progress", Journal of Personality, Vol. 76 No. 5, pp. 1201-1230.

Laurel, B. (2001), Utopian Entrepreneur, MIT Press, Cambridge, available at:

http://search.ebscohost.com/login.aspx?direct=true\&scope=site \&db=nlebk\&db=nlabk\&AN=138 674 (accessed 24 March 2014).

Lee, T. (2006), "This Is Not A Game: Alternate Reality Gaming and its potential for learning", Futurelab, July, available at: http://archive.futurelab.org.uk/resources/publications-reports-articles/webarticles/Web-Article477.

Lewis, C.S. (1953), The Silver Chair, 1st ed., Geoffrey Bles, United Kingdom.

Malone, T. and Lepper, M. (1987), “Making Learning Fun: A Taxonomy of Intrinsic Motivations for Learning", in Snow, R. and Farr, M.J. (Eds.), Aptitude, Learning, and Instruction, 1st ed., Vol. Volume 3: Conative and Affective Process Analyses, New Jersey, pp. 223-253.

Markey, K., Leeder, C. and Rieh, S.Y. (2014), Designing Online Information Literacy Games Students Want to Play, Rowman \& Littlefield, Plymouth.

Markey, K., Leeder, C., Swanson, F., Peters, G.S., Jennings, B., Jean, B.S., Rosenberg, V., et al. (2012), "BiblioBouts: A Scalable Online Social Game for the Development of Academic Research Skills", LOEX Conference Proceedings 2010, available at: http://commons.emich.edu/loexconf2010/12.

Markey, K., Swanson, F., Jenkins, A., Jennings, B.J., St. Jean, B., Rosenberg, V., Yao, X., et al. (2008), "The Effectiveness of a Web-based Board Game for Teaching Undergraduate Students Information Literacy Concepts and Skills", D-Lib Magazine, Vol. 14 No. 9/10, available at:https://doi.org/10.1045/september2008-markey. 
Martel, Y. (2001), Life Of Pi, 1st ed., Knopf, Canada.

Martin, A. and Chatfield, T. (2006), "What Is An ARG?", in Thompson, B. (Ed.), Alternate Reality Games White Paper, International Game Developer's Association, pp. 6-7.

Maybee, C. (2006), “Undergraduate Perceptions of Information Use: The Basis for Creating UserCentered Student Information Literacy Instruction", The Journal of Academic Librarianship, Vol. 32 No. 1 , pp. $79-85$.

McGonigal, J. (2003a), “A Real Little Game: The Performance of Belief in Pervasive Play”, DiGRA '03 Proceedings of the 2003 DiGRA International Conference: Level-Up, presented at the 2003 Digital Games Research Association International Conference: Level-Up, Digital Games Research Association, Utrecht, available at: http://www.avantgame.com/MCGONIGAL\%20A\%20Real\%20Little\%20Game\%20DiGRA\%202003 .pdf (accessed 24 March 2015).

McGonigal, J. (2003b), "This Is Not a Game: Immersive Aesthetics and Collective Play", Melbourne DAC 2003 Streamingworlds Conference Proceedings, RMIT University.

McGonigal, J. (2007), "The Puppet Master Problem: Design for Real-World, Mission Based Gaming”, Second Person, available at: http://www.waffler.org/wp-content/uploads/2009/05/the-puppetmaster-problem-design-for-real-world-mission-based-gaming1.pdf (accessed 16 March 2015). McGonigal, J. (2010), “Urgent Evoke: What Went Right, What Went Wrong: Lessons from Season 1 of EVOKE.", available at: http://blog.urgentevoke.net/2010/07/26/what-went-right-what-wentwrong-lessons-from-season-1-evoke1/ (accessed 23 March 2015).

Michael, D.R. and Chen, S.L. (2005), Serious Games: Games That Educate, Train, and Inform, 1st ed., Muska \& Lipman, Ohio.

Niemeyer, G., Garcia, A. and Naima, R. (2009), "Black Cloud: Patterns Towards Da Future", Proceedings of the 17th ACM International Conference on Multimedia, ACM, New York, pp. 1073-1082. 
Ornebring, H. (2007), "Alternate reality gaming and convergence culture: The case of Alias", International Journal of Cultural Studies, Vol. 10 No. 4, pp. 445-462.

Owusu-Ansah, E.K. (2004), "Information literacy and higher education: placing the academic library in the center of a comprehensive solution", Journal of Academic Librarianship, Vol. 30 No. 1, pp. 316.

Patton, M.Q. (1987), How to Use Qualitative Methods in Evaluation, Sage Publications.

Piatt, K. (2009), "Using alternate reality games to support first year induction with ELGG", Campus-Wide Information Systems, Vol. 26 No. 4, pp. 313-322.

Pickard, A.J. (2013), Research Methods in Information, Neal-Schuman, Chicago.

Powell, R.A., Single, H.M. and Lloyd, K.R. (1996), “Focus Groups in Mental Health Research: Enhancing the Validity of User and Provider Questionnaires", International Journal of Social Psychiatry, Vol. 42 No. 3, pp. 193-206.

Rusnak, P., Dobson, T. and Boskic, N. (2008), “Articulation of ecological values in alternate reality gaming: A case study of World Without Oil", Proceedings of the 2nd European Conference on Games Based Learning, Academic Conferences Limited, Spain, p. 383.

Simpson, J.A., Weiner, E.S.C. and Oxford University Press. (1989), The Oxford English Dictionary., Oxford University Press, Oxford.

Smale, M.A. (2011), "Learning Through Quests and Contests: Games in Information Literacy Instruction", Journal of Library Innovation, Vol. 2 No. 2, pp. 36-55.

Stenros, J., Holopainen, J., Waern, A., Montola, M. and Ollila, E. (2011), “Narrative friction in alternate reality games: Design insights from conspiracy for good", Proceedings of the 5th Digital Games Research Association Conference, presented at the DiGRA 2011: Think Design Play, Digital Games Research Association, Hilversum, pp. 1-17. 
Stewart, D.W. and Shamdasani, P.N. (1990), Focus Groups: Theory and Practice, 1st ed., Sage Publications, London.

Stewart, S. (2008), “Alternate reality games", Sean Stewart, Personal, , available at: http://www.seanstewart.org/interactive/args/ (accessed 27 February 2015).

Strauss, A. and Corbin, J.M. (1998), Basics of Qualitative Research: Techniques and Procedures for Developing Grounded Theory, 2nd ed., Sage Publications, London.

Suits, B. (1978), The Grasshopper: Games, Life, and Utopia, University of Toronto Press, Buffalo.

Szulborski, D. (2005), This Is Not a Game, New Fiction Publishing, United States of America.

Unfiction. (2002), "The Unfiction Glossary", available at: http://www.unfiction.com/glossary/ (accessed 28 February 2013).

University of Pretoria. (2016), "Yearbook Module Information", University of Pretoria, available at: http://www.up.ac.za/yearbooks/modules/view/AIM\%20101 (accessed 14 June 2016).

Waddington, D.I. (2013), “A parallel world for the World Bank: A case study of Urgent: Evoke, an educational alternate reality game", Revue Internationale Des Technologies En Pédagogie Universitaire, Vol. 10 No. 3, pp. 42-56.

Wadsworth, B.J. (1996), Piaget's Theory of Cognitive and Affective Development: Foundations of Constructivism, 5th ed., Longman Publishing, White Plains, available at: http://doi.apa.org/psycinfo/1996-97227-000 (accessed 13 November 2014).

Wempen, F. (2014), Computing Fundamentals: Digital Literacy Edition, 1st edition., Wiley, London. Whitton, N. (2009), Alternate Reality Games for Orientation, Socialisation \& Induction, Manchester Metropolitan University, available at: http://www.jisc.ac.uk/publications/reports/2009/argosifinalreport.aspx (accessed 14 May 2014). 
Whitton, N. (2011), "Game Engagement Theory and Adult Learning”, Simulation \& Gaming, Vol. 42 No. 5, pp. 596-609.

Whitton, N. and Jones, R. (2009), "Alternate reality gaming to support information literacy.", ALISS Quarterly, Vol. 4 No. 4, pp. 18-21.

Yang, T.A. (2001), "Computer Security and Impact on Computer Science Education", Proceedings of the Sixth Annual CCSC Northeastern Conference on The Journal of Computing in Small Colleges, Consortium for Computing Sciences in Colleges, Middlebury, pp. 233-246.

Yin, R.K. (2013), Case Study Research: Design and Methods, 5th ed., Sage Publications, Inc, Thousand Oaks, available at: (accessed 20 November 2014).

Zhang, D. and Nunamaker, J.F. (2003), “Powering e-learning in the new millennium: An overview of elearning and enabling technology", Information Systems Frontiers, Vol. 5 No. 2, pp. 207-218. 